\title{
Obez Bireylerde Vücut Kompozisyonu Bileşenlerinin Modellenmesi
}

\author{
Seda SERTEL MEYVACI ${ }^{1} \oplus \square$, Handan ANKARALI ${ }^{2} \bullet$ \\ ${ }^{1}$ Bolu Abant İzzet Baysal Üniversitesi Tip Fakültesi, Anatomi Anabilim Dalı, Bolu, Türkiye \\ ${ }^{2}$ İstanbul Medeniyet Üniversitesi Tip Fakültesi, Biyoistatistik ve Tip Bilişimi Anabilim Dalı, İstanbul, Türkiye
}

Bu makaleye yapılacak atıf: Sertel Meyvacı S, Ankaralı H. Obez Bireylerde Vücut Kompozisyonu Bileşenlerinin Modellenmesi. Turk J Diab Obes 2021;1: 1-6.

\begin{abstract}
ÖZ
Amaç: Bu çalışmada obez bireylerin vücut kompozisyon bileşenleri modellenerek vücut analizi cihazı ile ağırlığı ölçülemeyen morbid obezlerin vücut kompozisyon bileşenlerinin tahmininin yapılması amaçlandı.

Gereç ve Yöntemler: Beslenme ve Diyet Polikliniği’ne başvuran 160’1 kadın (\%75,5), 52’si erkek (\%24,5) olmak üzere toplam 212 yetişkin obez bireyin vücut kompozisyonu parametreleri retrospektif olarak incelendi. Yağ miktarı (YM), yağsiz doku miktarı (YDM), sıvı miktarı (SM) ve yağ yüzdesi (YY) gibi vücut kompozisyon ölçümleri segmental vücut analizi cihazı ile değerlendirildi. Ayrıca bireylerin yaşcinsiyet gibi demografik özellikleri ile boy uzunluğu ve beden kütle indeksi verileri hastane arşivinden alınarak incelendi. İstatistiksel analizlerde parametreler için ortalama, standart sapma ve yüzde değerleri kullanıldı. Çalışmada yer alan yaş-cinsiyet verileri ile boy uzunluğu, vücut ağırlı̆̆ı, YM, YDM, SM ve YY ölçümleri arasındaki ilişkilerden parametrik olmayan regresyon modeli kullanılarak 4 farklı model geliştirildi.

Bulgular: Geliştirilen modellerde yapılacak tahminlerdeki isabet derecesi en yüksek \%82,3 ile SM’de ve en düşük de \%50 olarak YY'de bulundu. Vücut ağırlığı, boy uzunluğu ve cinsiyetin vücut kompoziyonu bileşenleri üzerine etkisinin olduğu, yaşın ise bu parametreler üzerinde herhangi bir etki göstermediği saptandı.

Sonuç: Elde edilen sonuçlarımıza göre geliştirilen modellerle ağırlığı vücut analizi cihazı ile ölçülemeyen morbid obezlerde vücut kompozisyonu parametrelerinin tahmin edilebileceğini ve bu tahminlerin klinikte kullanılabileceği sonucuna varılmıştır. Çalışmamızın bu yönüyle literatüre katkı sağlayacağı düşünülmektedir.
\end{abstract}

Anahtar Sözcükler: Obezite, Modelleme, Biyoelektriksel impedans analizi, Vücut kompozisyonu, Parametrik olmayan regresyon modeli

\section{Modeling of Body Composition Components in Obese Individuals}

\begin{abstract}
Aim: In this study, it was purposed to estimate the body composition components of morbid obese individuals whose weight could not be measured with a body analysis device by modeling the body composition components of obese individuals.

Material and Methods: The body composition parameters of a total of 212 adult obese individuals, 160 female and 52 male, who applied to the Nutrition and Dietetics Outpatient Clinic, were analyzed retrospectively. Body composition measurements such as the amount of fat mass (FM), fat-free mass (FF), fluid mass (FD) and body fat percentage (FP) were evaluated with the segmental body analysis device. In addition, demographic characteristics of individuals such as age-gender, stature and Body Mass Index data were taken from the hospital archive and analyzed. Mean, standard deviation and percentage values were used for parameters in statistical analysis. Four different models were developed using the nonparametric regression model for the relationships between age-gender data in the study and stature, body weight, FM, FF, FD and FP measurements.

Results: The accuracy rate in the predictions to be made in the developed models was found as the highest $82.3 \%$ for FD and $50 \%$ for FP. It was found that body weight, stature and gender had an effect on components of body composition, whereas age had no effect on these parameters.
\end{abstract}

ORCID: Seda Sertel Meyvac1 / 0000-0002-9450-145X, Handan Ankaralı / 0000-0002-3613-0523 
Conclusion: It was concluded that models developed according to our results can estimate body composition parameters in morbid obese patients whose body weight be measured with a body analysis device and these estimates can be used in clinical practice. This aspect of our study is thought to contribute to the literature.

Key Words: Obesity, Modeling, Bioelectric impedance analysis, Body composition, Nonparametric regression model

\section{GIiRIS}

Vücut kompozisyonu ve obezite arasındaki ilişki çeşitli fizyolojik ve patolojik durumlarla ilgilidir. Bireysel vücut kompozisyonu bileşenlerinin karakterizasyonu, obezite ve obezite ile ilişkili metabolik risklerin anlaşılmasını sağlar (1). Vücut ağırlığındaki dinamik değişiklikler, vücut kompozisyonunda aşırı yağ dokusu gelişimi veya vücutta ağırlık kaybı sonucu oluşabilecek hastalıklar için önemli risk göstergeleri olarak kabul edilmektedir (2).

Bir sağlık problemi olan obezite durumu, vücut ağırlığının $(\mathrm{kg})$ boy uzunluğunun karesine $\left(\mathrm{m}^{2}\right)$ bölünmesiyle tespit edilen beden kütle indeksi (BKI) $30 \mathrm{~kg} / \mathrm{m}^{2}$ ve üzeri olan kişilerde tanımlanır. Ancak bu BKİ hesabı, obezite tanımından daha düşük BKİ derecelerine sahip fazla vücut ağırlığ 1 durumu ile ilişkili morbidite ve mortaliteyi veya karın içi yağlanmanın (abdominal obezitenin) zararlı etkisini dikkate almamaktadır (3).

Sağlık ve obezite gibi hastalık durumunda vücut kompozisyonunun değerlendirilmesinde kullanılan yöntemlerden biri de biyoelektriksel impedans analiz (BİA) cihazıdır. BİA, vücut kompozisyonu parametrelerinin tahmini için kullanımı kolay ve düşük maliyetli olmasından dolayı klinik pratikte yaygın olarak kullanılan bir yöntemdir. Biyolojik sistemlerde elektriksel iletim, sudaki iletkenlik ve iyonik dağılım ile ilgilidir. İletkenliğin yağ miktarı (YM)'nda, yağsız doku miktarı (YDM)'ndan çok daha fazla olması nedeniyle BİA yöntemi, doğrudan veya dolaylı olarak YM, YDM, sıvı miktarı (SM) ve yağ yüzdesi (YY)'nin tahminine izin vermektedir $(4,5)$.

Vücutta YDM'nin neredeyse tüm su miktarını ve iletken elektrolitleri içermesinden dolayı, YDM referans alınarak geliştirilen denklemler aracılığıyla BİA tarafından diğer vücut kompozisyonu parametreleri tahmin edilebilir. BİA tahmin modelleri, çoklu regresyon analizinde yer alan parametrelere ek olarak, türetildikleri ve onaylandıkları parametrelerin özelliklerine göre farklılık gösterir. BİA denklemlerini seçerken, örneğin yaş ve etnik kökenle ilgili farklılıklar BİA tahminlerini hassas bir şekilde etkileyebileceğinden, geliştirildiği ve onaylandığı örneğin özelliklerini dikkate almak önemlidir (5).

Bu çalışmamızda, obez bireylerde vücut kompozisyon ölçümleri ile vücut ağırlığı arasındaki doğrusal ve doğrusal olmayan ilişkileri, parametrik olmayan regresyon yöntemlerinden birisi olan çokdeğişkenli uyarlanabilir regresyon eğrileri (MARS) modeliyle incelenmesi ve tespit edilen ilişkilerin modellenerek tahmin amaçlı kullanımının sağlanması amaçlanmaktadır.

\section{GEREÇ ve YÖNTEMLER}

Bu çalışmada, Bolu Abant İzzet Baysal Üniversitesi Eğitim ve Araştırma Hastanesi, Beslenme ve Diyet Polikliniği'ne başvuran bireyler retrospektif olarak incelendi. Çalışmaya yaşı 18-68 yıl arasında olan, 160'ı kadın ve 52'si erkek olmak üzere toplam 212 yetişkin obez birey dahil edildi. Bireylerin BKİ $30-34,99 \mathrm{~kg} / \mathrm{m}^{2}$ arasında olmak üzere 1.derece obezite sinırlarında tutuldu.

Çalışmamız, Helsinki Deklarasyonu Prensipleri'ne uygun olarak yapıldı. Çalışma protokolü Bolu Abant İzzet Baysal Üniversitesi Klinik Araştırmalar Etik Kurulu tarafından onaylandı (Karar No:2019/106).

Ölçümler

Araştırmamızda bireylerin vücut kompozisyonu ölçümlerinden YM (kg), YDM (kg), SM (kg) ve YY (\%) olmak üzere dört parametre Tanita MC 580 segmental vücut analizi cihazı kullanılarak değerlendirildi ve bilgisayar sistemine kayıt edildi. Bu parametrelere ek olarak bireylerin yaş, boy uzunluğu, vücut ağırlığı ve BKİ verileri de bilgi işlem sistemi arşivinden alınarak değerlendirildi. Bütün ölçümler, yaş ve cinsiyet gibi demografik özellikler ile vücut kompozisyonu parametrelerinin istatistiksel analizleri yapılabilmesi için veriler Excel programına kayıt edildi.

\section{İstatistik Analiz}

Elde edilen verilere ait tanımlayıcı istatistikler ortalama, standart sapma ve yüzde olarak hesaplandı. Çalışmada ölçülen, YM, YDM, SM ve YY ile vücut ağırlı̆̆ı arasındaki ilişkiler modellendi. Ancak bu modellerde cinsiyet, yaş ve boy uzunluğu farklılıklarının etkileri de dikkate alınarak etkileri ortadan kaldırıldıktan sonraki düzeltilmiş değerler elde edildi. Modellerde, YM, YDM, SM ve YY bağımlı değişken, cinsiyet, yaş, boy uzunluğu ve vücut ağırlı̆̆ ise bağımsız değişken olarak kabul edildi. Boy uzunluğu ve vücut ağırlığı birlikte modele alındığı için bu iki özelliğin direkt fonksiyonu olan BKİ modele dahil edilmedi. Modelleme aşamasında, doğrusal ve doğrusal olmayan ilişkileri inceleme firsatı 
sunan MARS modeli kullanıldı. Hesaplamalarda $\mathrm{SPM}^{\circledR} 8$ (Trial version) kullanıldı. İstatistik anlamlılık düzeyi olarak $\mathrm{p}<0,05$ kabul edildi.

\section{BULGULAR}

Çalışmaya alınan 212 kişinin 160 'ı $(\% 75,8)$ kadın ve 52'si $(\% 24,2)$ erkek olmak üzere BKİ’si 30,01-34,89 kg/m² arasında değişmekteydi. Ayrıca yaş, boy uzunluğu, vücut ağırlığı, BKI, YM, YDM, SM ve YY'ye ait tanımlayıcı istatistikler Tablo 1'de verildi.

Cinsiyet, yaş, boy uzunluğu ve vücut ağırlığının, YM üzerine etkisi araştırıldığında, yaşın etkisi anlamlı bulunmadı $(\mathrm{p}=0,842)$, buna karşın cinsiyet $(\mathrm{p}=0,001)$, vücut ağırlığ 1 $(\mathrm{p}=0,001)$ ve boy uzunluğunun $(\mathrm{p}=0,041)$ YM üzerine anlamlı etki gösterdiği belirlendi. Bu üç değişken içinde en fazla vücut ağırlığının, sonra cinsiyet ve en az miktarda da boy uzunluğunun YM'yi etkilediği belirlendi. Bulunan sonuca göre aşağıdaki Model-1 elde edildi. Model incelendiğinde vücut ağırlığı 79,2 kg’nin altında olanlarda vücut ağırlığı 1 kg arttıkça YM 0,776 birim azalmakta, buna karşın vücut ağırllğı 80,2 kg'nin üstünde olanlarda ise vücut ağırlığının $1 \mathrm{~kg}$ artışında ise YM'nin 0,655 birim arttığ belirlendi. Ayrıca erkek cinsiyette yağ miktarının anlamlı düzeyde 9,249 kat daha az olduğu ve boy uzunluğu $159 \mathrm{~cm}$ 'nin üzerinde olanlarda ise boy uzunluğu $1 \mathrm{~cm}$ arttığında yağ miktarı 0,428 birim azaldığı belirlendi. Buna karşın boy uzunluğu 159 cm'den küçük olanlarda boy uzunluğu değişimi ile yağ miktarı arasında anlamlı bir ilişki bulunmadı. Kurulan Model-1'e göre yapılacak tahminlerdeki isabet derecesi $\% 52,5$ ve modelin hatası ise $(\mathrm{HKO}=$ Hata Kareler Ortalaması) 17,38 olarak hesapland 1 .

Yăg miktarı $=32,95-0,776$ * (Ağırlık $<79,2)+0,655^{*}$ $\left(\right.$ Ağırlık > 80,2) $-9,25{ }^{\star}$ Erkek - 0,428* $($ Boy $>159)$ Model-1

Cinsiyet, yaş, boy uzunluğu ve vücut ağırlığının, YDM üzerine etkisi araştırıldığında, yaşın etkisi anlamlı bulunmadı $(\mathrm{p}=0,283)$, buna karşın cinsiyet $(\mathrm{p}=0,001)$, vücut ağırlığı $(\mathrm{p}=0,001)$ ve boy uzunluğunun $(\mathrm{p}=0,008)$ YDM'yi anlamlı düzeyde etkilediği belirlendi. Bu 3 değişken içinde en fazla cinsiyetin, sonra vücut ağırlığı ve en az miktarda da boy uzunluğunun YDM'yi etkilediği belirlendi. Bulunan sonuca göre aşağıdaki Model-2 elde edildi. Model incelendiğinde boy uzunluğu $160 \mathrm{~cm}$ 'den kısa olanlarda boy uzunluğu ile YDM arasında anlamlı bir ilişki bulunmazken, boy uzunluğu $160 \mathrm{~cm}$ 'den uzun olanlarda boy uzunluğunun $1 \mathrm{~cm}$ artış1 ile YDM'nin 0,458 birim arttığı görüldü. Ayrıca erkek cinsiyette YDM'nin anlamlı düzeyde 8,441 kat fazla olduğu ve vücut ağırlığ $1 \mathrm{~kg}$ arttığında YDM'nin de anlamlı düzeyde 0,313 kat arttığ görüldü. Kurulan bu modele göre yapılacak tahminlerdeki isabet derecesi \%82,3 ve modelin hatası ise (HKO=Hata Kareler Ortalaması) 17,23 olarak hesaplandı.

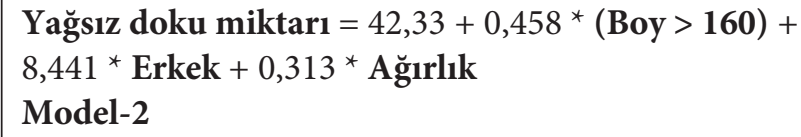

Cinsiyet, yaş, boy uzunluğu ve vücut ağırlığının SM üzerine etkisi araştırıldığında, yaşın etkisi anlamlı bulunmadı $(\mathrm{p}=0,128)$, buna karşın cinsiyet $(\mathrm{p}=0,001)$, vücut ağırlığı $(\mathrm{p}=0,001)$ ve boy uzunluğunun $(\mathrm{p}=0,049)$ SM'yi anlam1 düzeyde etkilediği belirlendi. Bu üç değişken içinde en fazla cinsiyet, sonra vücut ağırlı̆̆ı ve en az miktarda da boy uzunluğunun SM'yi etkilediği belirlendi. Bulunan sonuca göre aşağıdaki Model-3 elde edildi. Model incelendiğinde boy uzunluğu $160 \mathrm{~cm}$ 'den kısa olanlarda boy uzunluğu ile SM arasında anlamlı bir ilişki yokken, boy uzunluğu 160 cm'den uzun olanlarda boy uzunluğunun $1 \mathrm{~cm}$ artması ile SM'nin de 0,323 birim arttığı görüldü. Ayrıca erkek cinsiyette SM'nin anlamlı düzeyde 7,23 kat fazla olduğu ve vücut ağırlı̆̆ının $1 \mathrm{~kg}$ artması ile SM'nin de anlamlı düzeyde 0,216 kat arttığ görüldü. Kurulan bu modele göre yapılacak tahminlerdeki isabet derecesi $\% 83,7$ ve modelin hatası ise (HKO=Hata Kareler Ortalaması) 8,85 olarak hesapland 1.

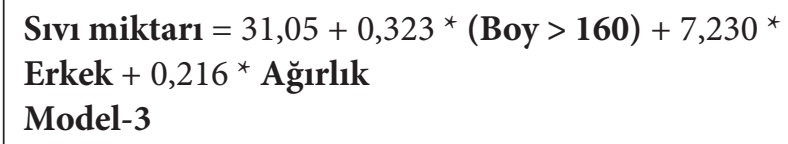

Tablo 1: Sayısal tipte özelliklere ait tanımlayıcı istatistikler $(\mathrm{n}=212)$

\begin{tabular}{lccc}
\hline & Ortalama \pm Standart Sapma & Minimum & Maksimum \\
\hline Yaș (yıl) & $34,47 \pm 13,03$ & 18 & 68 \\
\hline Vücut Ağırlı̆̆ı (kg) & $87,03 \pm 10,35$ & 64,1 & 118,6 \\
\hline Boy Uzunluğu (cm) & $163,72 \pm 9,02$ & 142 & 189 \\
\hline Yağ Miktarı (kg) & $32,56 \pm 6,13$ & 18,40 & 55,75 \\
\hline Yağsız Doku Miktarı (kg) & $54,10 \pm 10$ & 22,30 & 85,80 \\
\hline Sıvı Miktarı (kg) & $39,53 \pm 7,46$ & 15,7 & 62,8 \\
\hline Yă̆ Yüzdesi (\%) & $37,66 \pm 6,96$ & 20,16 & 70,30 \\
\hline
\end{tabular}


Cinsiyet, yaş, boy uzunluğu ve vücut ağırlığının, YY üzerine etkisi araştırıldığında, yaşın etkisi anlamlı bulunmadı $(\mathrm{p}=0,743)$, buna karşın cinsiyet $(\mathrm{p}=0,001)$, vücut ağırlı̆̆ 1 $(\mathrm{p}=0,004)$ ve boy uzunluğunun $(\mathrm{p}=0,049)$ YY'yi anlamlı düzeyde etkilediği belirlendi. Bu üç değişken içinde en fazla cinsiyet, sonra vücut ağırlığ uzunluğunun YY'yi etkilediği belirlendi. Bulunan sonuca göre aşağıdaki Model-4 elde edildi. Model incelendiğinde vücut ağırlığ 76,8 kg'nin altında olanlarda vücut ağırlı̆̆ 1 ile YY arasında anlamlı ilişki bulunmazken, vücut ağırlı̆̆ 1 76,8 kg'nin üstünde olanlarda vücut ağırlığı $1 \mathrm{~kg}$ arttığında YY'nin 0,323 birim arttığ belirlendi. Ayrıca erkek cinsiyette YY'nin anlamlı düzeyde 10,608 kat daha az olduğu görüldü. Bunun yanı sıra boy uzunluğu $159 \mathrm{~cm}$ 'nin üzerinde olanlarda ise boy uzunluğu $1 \mathrm{~cm}$ arttığında YY'nin 2,092 birim azaldığ 1 ancak boy uzunluğu $159 \mathrm{~cm}$ 'nin altında olanlarda boy uzunluğu $1 \mathrm{~cm}$ arttığında YY'nin 1,60 kat arttığı belirlendi. Kurulan Model-4'e göre yapılacak tahminlerdeki isabet derecesi $\% 50$ olarak hesapland. Modelin hatası ise (HKO=Hata Kareler Ortalaması) 23,55 olarak hesaplandı.

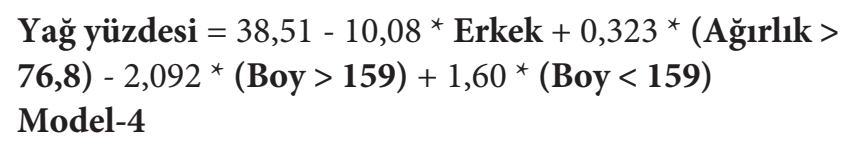

\section{TARTIŞMA}

Biyoelektriksel impedans analiz yönteminin vücut kompozisyonlarının değerlendirilmesinde kullanılması güvenilir sonuçlar verdiğinden özellikle klinik ve sağlık açısından değerlendirmelerde dikkate alınması gerektiği bildirilmiştir (6).

Vücut kompozisyonunu etkileyecek bütün faktörlerin bilinmesi, yapılacak çalışmaların doğru planlanmasında, bireysel farklılıkları dikkate alarak araştırmalarda doğru sonuçların elde edilmesinde önemlidir ve daha fazla bilgi gerektirmektedir. Bu vücut kompozisyonu parametreleri, yaş, boy uzunluğu, vücut ağırlığı, cinsiyet, etnik köken ve yaşam tarzı başta olmak üzere birçok faktörden etkilenmektedir. Bu nedenle vücut kompozisyonunu etkileyen faktörler dikkate alınarak planlanmış birçok araştırma yapılmıştır (7-9).

Yapılmış araştırmaları incelediğimizde birçok araştırmacı, vücut kompozisyonunu etkileyen faktörler ile birbiri arasındaki ilişkiyi incelemişlerdir. Yaş ve cinsiyet başta olmak üzere bu faktörlerin, vücut kompozisyonu parametreleri sonuçları üzerine etkisini araştırmalarında ortaya koymuşlardır $(10,11)$. Çalışmamızda vücut kompozisyonu parametreleri olan YM, YDM, SM ve YY ile vücut ağırlığı değeri arasındaki ilişki obez bireylerde her iki cinsiyet üzerinde incelendi.
Vücut kompozisyonu ile vücut ağırlığı arasındaki ilişkiyi inceleyen birçok araştırmacı, beslenme, zayıflık, obezite üzerine çalışmalar yapmışlardır (12-14). Bu araştırmalarda vücut kompozisyonu parametrelerinin değerlendirilmesinde zararsız ve ucuz bir yöntem olmasından dolayı BİA başta olmak üzere, çift enerjili X-ışını absorbsiyometrisi (DEXA) ve manyetik rezonans görüntüleme (MR) teknikleri kullanılmıştır (15-17). Vücut kompozisyonlarını incelediğimiz araştırmamizda YM, YDM, SM ve YY parametrelerini BİA cihazı kullanarak obez bireylerde belirleyerek değerlendirdik.

Vücut kompozisyonundaki değişiklikler, dikkate alınması gereken ve parametrelerin sonuç değerlerinin etkileyecek çalışmaların başında obeziteli bireylerin vücut ağırlı̆̆ının artmasına yönelik araştırmalar gelmektedir. Diğer araştırmaları incelediğimizde vücut kompozisyonunun incelenmesini gerektiren, sporcuların değerlendirilmesinde, çeşitli hastalık durumlarında ve sağlıklı bireylerde vücut kompozisyonu parametreleri dikkate alınmıştır (18-20).

Özellikle vücut kompozisyonu parametrelerin ölçümleri ile vücut ağırlığı, boy uzunluğu ve bu parametrelerden üretilen BKİ arasındaki ilişkiyi inceleyen sınırlı araştırma olduğunu gördük (21). Rush ve ark. yapmış oldukları çalışmada, logaritmik BKİ üzerine YY'nin etkisi araştırılırken yaş kovaryat, cinsiyet ve etnik köken ise grup olarak modele alınmıştır (21). Kadın ve erkeklerin logaritmik eğrileri arasında anlamlı fark bulunmuştur ( $\mathrm{p}<0,0001)$. Bu nedenle kadın ve erkekler için ayrı ayrı model oluşturulmuştur. Deurenberg ve ark. tarafından yapılan araştırmada cinsiyet, yaş ve BKİ’nin bağımlı değişken olarak YY üzerine etkisini incelemişler. Bağımsız değişkenler BKİ arasındaki regresyon ilişkisini yaş ve cinsiyete göre inceledikleri bu araştırmada kurulan modele göre yapılacak tahminlerdeki cinsiyetin tek başına YY'nin isabet derecesini \%50, cinsiyet, yaş, BKİ değişkenleri bir araya geldiğinde ise isabet derecesi \%88 olarak hesaplamışlardır (22).

Bizim çalışmamızda ise obez bireylerde YM, YDM, SM ve YY gibi vücut kompozisyon ölçümleri ile vücut ağırlığı arasındaki doğrusal ve doğrusal olmayan ilişkileri, modern regresyon tekniği ile araştırdık. Elde edilen bulgular değerlendirildiğinde, cinsiyet, yaş, boy uzunluğu ve vücut ağırllğının vücut kompozisyonu parametreleri üzerine etkisi araştırıldı ve her parametre için model kuruldu. Kurulan modellere göre yapılacak tahminlerdeki isabet derecesi YM'de \%52,5, YDM'de \%82,3, SM'de \%83,7 ve YY'de \%50 sonucuna ulaşıldı. Deurenberg ve ark.nın yaptığ 1 çalışma ile sonuçlarımız karşılaştırıldığında benzer olduğunu gördük (22). Çalışmamızda farklı olarak her parametre için model kuruldu. Çalışmamızda yaş dışında cinsiyet, boy uzunluğu ve vücut ağırlığının vücut kompozisyonu parametreleri üzerine etkisi olduğu bulundu. 
Vücut kompozisyonu bileşenlerinin değerlendirilmesinde kullanılan en etkin yöntemler arasında olan BİA'nın kullanımında son yıllarda artış olduğu görülmüştür (23). BİA yöntemi, yetişkin bireylerde ve en önemlisi de çocuklarda uygulanabilir olması, tekrar edilebilirliği, sonuçları hızlı vermesi, girişimsel olmaması ve zarar vermemesi yönüyle klinik ve epidemiyolojik çalışmalar için uygundur (6).

Çalışmamızın sonucunda, vücut ağırlığı ile YM, YDM, SM ve YY olmak üzere vücut kompozisyonu parametrelerinin hepsi ile arasında ilişkili olduğu tespit edildi. Yaş aralığını sınırlamadığımız çalışmamızda, vücut kompozisyonu parametreleri üzerine yaşın etkisi olmadığı bulundu. Vücut kompozisyonu parametrelerini etkileyen tüm faktörlerin içinde en fazla cinsiyetin, bunu vücut ağırlığı, en az miktarda da boy uzunluğunun izlediği belirlenmiştir ve bu bilgiler literatüre kazandırılmıştır.

Çalışmamızda ayrıca tüm vücut kompozisyonu parametrelerinden her biri için farklı model kurulmuştur. Cinsiyet, boy uzunluğu ve vücut ağırlığı dikkate alınarak kurulan bu modellerle yapılacak vücut kompozisyonu parametrelerinin tahminlerdeki isabet dereceleri ortaya koyulmuştur.

Tüm bu veriler ışı̆̆ında değerlendirildiğinde vücut kompozisyonu parametreleri ile başta vücut ağırlığ cinsiyet ve boy uzunluğu arasındaki ilișki anlamlı bulunmuştur. Vücut kompozisyonu parametreleri, vücut analizi cihazı ile ağırlığı ölçülemeyen morbid obez bireyler başta

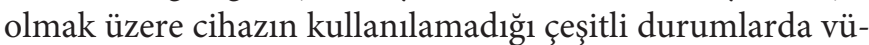
cut kompozisyonu bileşenlerinin tahmini değerlerini ortaya koymayı sağlayacaktır. Bu sonuç ile birlikte vücut kompozisyonu bileşenlerinin değerlendirilmesine ve ileride yapılacak klinik araştırmaların planlanmasına katkı sağlayarak yararlı olabileceği kanısındayız.

Teşekkür

Yazarlar, araștırmalarındaki parametrelerin ölçümlerini yapan Bolu Abant İzzet Baysal Üniversite Hastanesi Diyetisyenlerine ve araştırmalarına katkıda bulunan tüm gönüllülere teşekkür eder.

Yazarların Makaleye Katkı Beyanı

Çalışma konusunun belirlenmesi ve çalışmanın düzenlenmesi: Seda Sertel Meyvacı, Handan Ankaralı, Verilerin toplanmasi: Seda Sertel Meyvacı, Veri analizi ve yorumlama: Handan Ankaralı, Makalenin yazımı: Seda Sertel Meyvacı, Handan Ankaralı, Çalışmanın gözden geçirilmesi ve son onay: Seda Sertel Meyvacı, Handan Ankaralı.

Çıkar Çatışması

Yazarların herhangi bir çıkar çatışması bulunmamaktadır.

Finansal Destek

Araştırmamızda herhangi bir maddi destek kullanılmamıştır.

\section{Etik Kurul Onayı}

Çalışma protokolü Bolu Abant İzzet Baysal Üniversitesi Klinik Araştırmalar Etik Kurulu tarafından onaylandı (Karar No:2019/106).

\section{Hakemlik Süreci}

Yazı, kör hakemlik süreci sonrası yayınlanmaya uygun bulunmuş ve kabul edilmiştir.

\section{KAYNAKLAR}

1. Müller MJ, Lagerpusch M, Enderle J, Schautz B, Heller M, Bosy-Westphal A. Beyond the body mass index: Tracking body composition in the pathogenesis of obesity and the metabolic syndrome. Obes Rev. 2012;13:6-13.

2. Dulloo AG, Jacquet J, Solinas G, Montani JP, Schutz Y. Body composition phenotypes in pathways to obesity and the metabolic syndrome. Int J Obes. 2010;34:4-17.

3. Kopelman PG. Obesity as a medical problem. Nature. 2000;404:635-643.

4. Marra M, Sammarco R, De Lorenzo A, Iellamo F, Siervo M, Pietrobelli A, Donini LM, Santarpia L, Cataldi M, Pasanisi F, Contaldo F. Assessment of body composition in health and disease using Bioelectrical Impedance Analysis (BIA) and Dual Energy X-Ray Absorptiometry (DXA): A critical overview. Contrast Media Mol Imaging. 2019;2019:3548284.

5. Sergi G, De Rui M, Stubbs B, Veronese N, Manzato E. Measurement of lean body mass using bioelectrical impedance analysis: A consideration of the pros and cons. Aging Clin Exp Res. 2017;29:591-597.

6. Kaya H, Özçelik O. Vücut bileşimlerinin değerlendirilmesinde vücut kitle indeksi ve biyoelektrik impedans analiz metodlar1nın etkinliğinin yaş ve cinsiyete göre karşılaştırılması. FÜ Sağ Bil Tip Derg. 2009;23:1-5.

7. Meleleo D, Bartolomeo N, Cassano L, Nitti A, Susca G, Mastrototaro G, Armenise U, Zito A, Devito F, Scicchitano $\mathrm{P}$, Ciccone MM. Evaluation of body composition with bioimpedence. A comparison between athletic and. Eur J Sport Sci. 2017;17:710-719.

8. Willoughby D, Hewlings S, Kalman D. Body composition changes in weight loss: Strategies and supplementation for maintaining lean body mass, a brief review. Nutrients. 2018;10(12):1876.

9. Heo M, Kabat GC, Gallagher D, Heymsfield SB, Rohan TE. Optimal scaling of weight and waist circumference to height for maximal association with DXA-measured total body fat mass by sex, age and race/ethnicity. Int J Obes. 2013;37:11541160.

10. St-Onge MP, Gallagher D. Body composition changes with aging: The cause or the result of alterations in metabolic rate and macronutrient oxidation? Nutrition. 2010;26:152-155.

11. Lim S, Joung H, Shin CS, Lee HK, Kim KS, Shin EK, Kim HY, Lim MK, Cho SI. Body composition changes with age have gender-specific impacts on bone mineral density. Bone. 2004;35:792-798. 
12. Reinders I, Visser M, Schaap L. Body weight and body composition in old age and their relationship with frailty. Curr Opin Clin Nutr Metab Care. 2017;20:11-15.

13. Jahan MA. The role of source of protein in regulation of food intake, satiety, body weight and body composition. J Nutr Heal Food Eng. 2017;6:186-193.

14. Lavie CJ, De Schutter A, Patel DA, Romero-Corral A, Artham SM, Milani RV. Body composition and survival in stable coronary heart disease: Impact of lean mass index and body fat in the 'obesity paradox'. J Am Coll Cardiol. 2012;60:13741380.

15. Wong R, Barker J, Berreth T, Fox R, Maldonado M, Vancleave C, Zaragoza J, Tinnin M, Tinsley GM, Taylor LW IV, Brennan $\mathrm{K}$. The effects of acute resistance exercise on bioelectrical impedance analysis measures of body composition. Doctor of Physical Therapy Program; Mayborn College of Health Sciences; University of Human Performance Lab; School of Exercise and. 60. International Journal of Exercise Science: Conference Proceedings. 2020.

16. Verduin WM, Van Den Helder R, Doodeman HJ, Struijf E, Houdijk APJ. Dexa body composition assessment in 10-11 year healthy children. PLoS One. 2016;11:1-9.

17. West J, Leinhard OD, Romu T, Collins R, Garratt S, Bell JD, Borga M, Thomas L. Feasibility of MR-based body composition analysis In large scale population studies. PLoS One. 2016;11:1-14.
18. Seabolt LA, Welch EB, Silver HJ. Imaging methods for analyzing body composition in human obesity and cardiometabolic disease. Ann NY Acad Sci. 2015;1353:41-59.

19. Guppy FM, Wallace JA. The measurement of body composition in an athletic population: The importance of DXA. Meas Control (United Kingdom). 2012;45: 177-181.

20. Mersebach H, Svendsen OL, Holst JJ, Astrup A, FeldtRasmussen U. Comparisons of leptin, incretins and body composition in obese and lean patients with hypopituitarism and healthy individuals. Clin Endocrinol (Oxf). 2003;58:6571.

21. Rush EC, Freitas I, Plank LD. Body size, body composition and fat distribution: Comparative analysis of European, Maori, Pacific Island and Asian Indian adults. Br J Nutr. 2009;102:632-641.

22. Deurenberg P, Yap M, Van Staveren WA. Body mass index and percent body fat: A meta analysis among different ethnic groups. Int J Obes. 1998;22:1164-1171.

23. Çetin İ, Muhtaroğlu S, Yılmaz B, Kurtoğlu S. Evaluation of segmental body composition by gender in obese children using bioelectric impedance analysis method. Dicle Tip Derg. $2015 ; 42$. 